\title{
AKTIVITAS EKSTRAK METANOL KULIT PISANG (Musa paradisiaca L.) SEBAGAI ANTITUKAK LAMBUNG PADA TIKUS PUTIH (Rattus norvegicus)
}

\author{
Ekwan Prasetyo Azlin, Risna Agustina, Rolan Rusli* \\ Laboratorium Penelitian dan Pengembangan FARMAKA TROPIS Fakultas Farmasi \\ Universitas Mulawarman, Samarinda, Kalimantan Timur \\ *email: rolan@farmasi.unmul.ac.id
}

\begin{abstract}
Methanol extract of banana peels are known to have good antioxidant activity and empirically consumed for overcoming disorders of the stomach so that this study will examine the activities of the methanol extract of banana peel as anti-gastric ulcer. Gastric ulcer induced by ethanol orally to each test animal. The test animals were divided into 5 groups randomly: negative control group oral by NaCMC 0.5\%; positive control group oral by Sucralfate $80 \mathrm{mg} / 200 \mathrm{~g}$; test group 1, 2, 3 and 4 were given the methanol extract of banana peels at a dose of $60 \mathrm{mg} / 200 \mathrm{~g}, 70 \mathrm{mg} / 200 \mathrm{~g}, 80 \mathrm{mg} / 200 \mathrm{~g}$ and $90 \mathrm{mg} / 200$ g. Observations gastric ulcer condition was assessed using Ulcer Index (UI) and Prevention Strength (PS). The results of data analysis showed that three doses of the test have a different activity with the negative control group significantly ( $p<0.05)$. Methanol extract of banana peels has a potential as anti-gastric ulcer with an effective dose was 80 $m g / 200 \mathrm{~g}$.
\end{abstract}

Keyword: Ulcer Index, gastric ulcer, banana peel

\begin{abstract}
ABSTRAK
Ekstrak metanol kulit pisang diketahui memiliki aktivitas antioksidan yang cukup baik dan secara empiris kulit pisang terkadang dikonsumsi untuk mengatasi gangguan pada lambung sehingga penelitian ini akan menguji aktivitas ekstrak metanol kulit pisang sebagai antitukak lambung. Induksi tukak lambung dilakukan dengan menggunakan etanol secara oral pada tiap hewan uji. Hewan uji dibagi menjadi 5 kelompok secara acak yaitu kelompok kontrol negatif yang diberi NaCMC $0,5 \%$; kelompok kontrol positif yang diberi Sukralfat $80 \mathrm{mg} / 200 \mathrm{~g} \mathrm{BB}$; kelompok uji 1, 2, 3 dan 4 diberi ekstrak metanol kulit pisang dengan dosis $60 \mathrm{mg} / 200 \mathrm{~g} \mathrm{BB}, 70 \mathrm{mg} / 200 \mathrm{~g} \mathrm{BB}, 80 \mathrm{mg} / 200 \mathrm{~g} \mathrm{BB}$ dan $90 \mathrm{mg} / 200 \mathrm{~g} \mathrm{BB}$. Pengamatan kondisi tukak lambung dinilai dengan menggunakan Indeks Tukak (IT) dan Daya Pencegahan (DP). Hasil analisis data menunjukkan bahwa ketiga dosis uji memiliki aktivitas yang berbeda bermakna $(\mathrm{p}<0,05)$ dengan kelompok kontrol negatif. Ekstrak metanol kulit pisang memiliki potensi sebagai antitukak lambung dengan dosis efektif sebesar $80 \mathrm{mg} / 200 \mathrm{~g} \mathrm{BB}$.
\end{abstract}

Kata kunci: indeks tukak, tukak lambung, kulit pisang

\section{PENDAHULUAN}

Tukak lambung dapat diartikan sebagai kondisi luka pada lambung atau usus duodenum karena ketidakseimbangan antara faktor agresif seperti sekresi asam lambung, 
pepsin, dan infeksi bakteri Helicobacter pylori dengan faktor defensif/pelindung mukosa seperti produksi prostaglandin, gastric muсus, bikarbonat, dan aliran darah mukosa. (Johnson, 2007).

Gaya hidup atau kebiasaan seseorang dapat pula menjadi pemicu munculnya penyakit tukak lambung seperti merokok, mengonsumsi obat-obat NSAID (Non Steroidal Anti Inflammatory Drugs) dan meminum alkohol dalam jangka panjang. Rokok, obat-obat NSAID dan alkohol merupakan bahan-bahan yang dapat bersifat radikal bebas dalam tubuh dan lambung yang merupakan organ pencernaan dapat pula terkena efek dari radikal bebas tersebut. Efek radikal bebas dapat menyebabkan terjadinya kerusakan pada mukosa lambung sehingga pada akhirnya menimbulkan luka pada dinding lambung.

Penggunaan bahan dari alam sebagai obat tradisional dapat menjadi alternatif bagi masyarakat untuk semakin mengembangkan penggunaan obat-obat tradisional. Salah satu bahan alami yang digunakan oleh masyarakat sebagai obat tradisional yaitu kulit pisang. Masyarakat ada yang menggunakan kulit pisang untuk perawatan pada kulit dan mencegah penuaan.

Menurut Pane (2013), ekstrak metanol kulit pisang memiliki aktivitas antioksidan. Hal tersebut dikarenakan kandungan flavonoid yang terdapat pada kulit pisang. Atun, dkk (2007) telah berhasil mengisolasi senyawa flavonoid yang diduga memiliki aktivitas antioksidan yaitu 5,6,7,4'-tetrahidroksi-3,4-flavan-diol.

Flavonoid yang memiliki banyak gugus $-\mathrm{OH}$ berpotensi dalam menangkal senyawa radikal bebas pada lambung. Selain itu menurut Atzingen, dkk (2013), gel dari kulit pisang memiliki efek penyembuhan terhadap luka karena kandungan flavonoid, tannin, saponin, dan steroid di dalamnya. Sehingga terdapat potensi kulit pisang dalam menyembuhkan kondisi luka pada lambung.

\section{METODE PENELITIAN}

\section{Bahan}

Bahan yang digunakan dalam penelitian ini yaitu aquadest, metanol, etanol $96 \%$, sukralfat, $\mathrm{Na}-\mathrm{CMC}$ dan $\mathrm{NaCl}$ fisiologis.

\section{Peralatan}

Peralatan yang digunakan dalam peneitian ini yaitu gelas ukur, labu ukur, kaca pembesar, oven, rotary evaporator, spoit, sonde, water bath dan timbangan analitik.

\section{Penyiapan Simplisia}

Sampel yang digunakan yaitu kulit pisang (Musa paradisiaca Linn.) yang terlebih dahulu dicuci dan kemudian dikeringkan di dalam oven pada suhu $50^{\circ} \mathrm{C}$. Selanjutnya simplisia yang telah kering dipotong hingga kecil dan ditimbang sebanyak $500 \mathrm{~g}$ untuk diekstraksi.

\section{Pembuatan Ekstrak Metanol Kulit Pisang}

Simplisia kulit pisang diekstraksi dengan metode maserasi dengan menggunakan pelarut metanol. Simplisia kulit pisang ditimbang sebanyak $500 \mathrm{~g}$ kemudian dimasukkan ke dalam wadah maserasi. Selanjutnya ditambahkan pelarut metanol hingga simplisia terendam di dalam wadah maserasi dan kemudian diaduk. Wadah ditutup dan dibiarkan selama 3-5 hari sambil diaduk setiap 24 jam. Hasil maserasi berupa ekstrak cair kemudian disaring hingga diperoleh filtrat dan residu. Residu diekstraksi kembali dengan metode maserasi (remaserasi) dengan menggunakan pelarut metanol. Filtrat diuapkan dengan 
menggunakan rotary evaporator pada suhu $55^{\circ} \mathrm{C}$ hingga diperoleh ekstrak kental. Ekstrak kental diuapkan pada suhu kamar hingga pelarut menguap dan didapatkan ekstrak kering.

\section{Penyiapan Hewan Uji}

Hewan uji yang digunakan pada penelitian ini yaitu tikus putih (Rattus norvegicus) sebanyak 18 ekor dengan berat badan 200-240 gram dan usia 2-3 bulan yang dibagi menjadi 6 kelompok yaitu 1 kelompok kontrol negatif, 1 kelompok kontrol positif dan 4 kelompok uji dosis eksttrak metanol kulit pisang. Masing-masing kelompok terdiri atas 3 ekor tikus putih. Tikus putih terlebih dahulu diaklimatisasi selama 1 minggu di kandang hewan uji Fakultas Farmasi Universitas Mulawarman dengan tujuan agar hewan uji beradaptasi dengan lingkungannya sebelum dilakukan pengujian.

\section{Pengujian Aktivitas Antitukak Lambung}

Sebelum pengujian, hewan uji terlebih dahulu dipuasakan selama kurang lebih 12 jam dengan tetap diberi air minum. Pada hari pertama seluruh hewan coba diinduksi dengan etanol $96 \%$ sebanyak $1 \mathrm{~mL}$ dan 24 jam kemudian masing-masing kelompok diberi perlakuan sebagai berikut: (1) kontrol negatif: diberi Na CMC 0,5\%; (2) kontrol positif: diberi suspensi sukralfat dengan dosis $72 \mathrm{mg} / 200 \mathrm{~g}$ BB tikus; (3) uji 1 (D1): diberi suspensi ekstrak metanol kulit pisang dengan dosis $60 \mathrm{mg} / 200 \mathrm{~g} \mathrm{BB}$; (4) uji 2 (D2): diberi suspensi ekstrak metanol kulit pisang dengan dosis $70 \mathrm{mg} / 200 \mathrm{~g} \mathrm{BB}$; (5) uji 3 (D3): diberi suspensi ekstrak metanol kulit pisang dengan dosis $80 \mathrm{mg} / 200 \mathrm{~g} \mathrm{BB}$; (6) uji 4 (D4): diberi suspensi ekstrak metanol kulit pisang dengan dosis $90 \mathrm{mg} / 200 \mathrm{~g} \mathrm{BB}$

Perlakuan tersebut dilakukan satu kali sehari selama tiga hari. Pada hari selanjutnya hewan uji disiapkan untuk dilakukan penentuan indeks tukak lambung. Hewan uji dipuasakan terlebih dahulu selama 12 jam. Selanjutnya hewan dikorbankan dengan menggunakan kloroform. Hewan uji dibedah abdomennya dan diambil lambungnya dengan cara memotong duodenum dan eshopagus et cardia. Lambung dibentangkan dan diamati kondisi dinding lambung dengan menggunakan kaca pembesar. Dihitung jumlah dan diameter atau panjang tukak yang terbentuk. Dicatat dan dihitung indeks tukak berdasarkan skor penilaian indeks tukak oleh Fitrianingsih dan Choesrina (2011) serta daya pencegahan dari masing-masing hewan uji tiap kelompok.

\section{Analisis Data}

Parameter yang diukur pada penelitian ini adalah indeks tukak lambung yang dianalisis dengan menggunakan ANOVA satu arah dan dilakukan uji lanjutan yang sesuai.

\section{HASIL DAN PEMBAHASAN}

\section{Aktivitas Antitukak Lambung Ekstrak Metanol Kulit Pisang}

Pengujian aktivitas antitukak lambung ekstrak metanol kulit pisang dilakukan dengan terlebih dahulu diinduksikan etanol $96 \%$ per oral untuk mengondisikan lambung hewan uji dalam keadaan tukak. Etanol dapat menyebabkan terjadinya difusi balik $\mathrm{H}^{+}$dari lumen masuk ke dalam mukosa lambung sehingga terjadi peningkatan sekresi asam lambung (Tarnawski, 2004). Sehingga etanol dapat memicu reaksi radikal bebas dalam tubuh khususnya pada lambung.

Pada tabel 3 menunjukkan indeks tukak lambung pada tiap kelompok pada hari ke-4. Kontrol negatif digunakan untuk mengetahui aktivitas ekstrak metanol kulit pisang sebagai antitukak lambung dengan membandingkannya dengan kelompok uji 1,2 dan 3 . Sedangkan kontrol positif digunakan untuk mengetahui adanya potensi dari ekstrak nmetanol kulit pisang sebagai antitukak lambung. 
Dilihat dari tabel tersebut diketahui bahwa ekstrak metanol kulit pisang memiliki aktivitas sebagai antitukak lambung karena terjadi penurunan rerata indeks tukak lambung seiring dengan adanya peningkatan dosis ekstrak. Data indeks tukak lambung dianalisis dengan ANAVA satu arah. Hasil analisis menunjukkan adanya perbedaan yang signifikan antara kelompok uji dengan kelompok kontrol negatif terhadap rerata indeks tukak lambung dengan nilai $p<0,05$. Ekstrak metanol kulit pisang mulai memberikan aktivitas pada dosis $70 \mathrm{mg} / 200 \mathrm{~g} \mathrm{BB}$. Pada dosis $60 \mathrm{mg} / 200 \mathrm{~g}$ BB belum memberikan aktivitas dilihat dari rerata indeks tukak yang dihasilkan sama dengan rerata indeks tukak dari kelompok kontrol negatif.

Tabel 1. Indeks tukak lambung masing-masing kelompok

\begin{tabular}{ccccccc}
\hline \multirow{2}{*}{ Kelompok } & \multicolumn{3}{c}{ Indeks Tukak } & \multirow{2}{*}{ Jumlah } & \multirow{2}{*}{ Rata-rata \pm SD } \\
\cline { 2 - 4 } & $\mathbf{n}_{\mathbf{1}}$ & $\mathbf{n}_{\mathbf{2}}$ & $\mathbf{n}_{\mathbf{3}}$ & & \\
\hline K(-) & 17 & 18 & 19 & 53 & $18,00 \pm 1,00$ \\
$\mathbf{D}_{\mathbf{1}}$ & 18 & 18 & 18 & 54 & $18,00 \pm 0,00$ \\
$\mathbf{D}_{\mathbf{2}}$ & 8,6 & 14,6 & 14,6 & 37,8 & $12,60 \pm 3,46$ \\
$\mathbf{D}_{3}$ & 5,3 & 5,3 & 7,3 & 17,9 & $5,97 \pm 1,15$ \\
$\mathbf{D}_{\mathbf{4}}$ & 2 & 2 & 2 & 6 & $2 \pm 0,00$ \\
$\mathbf{K}(+)$ & 7,3 & 5,3 & 5,3 & 17,9 & $5,97 \pm 1,15$ \\
\hline
\end{tabular}

Aktivitas antitukak lambung pada ekstrak metanol kulit pisang dapat dihubungkan dengan adanya metabolit sekunder yang berperan dalam menyembuhkan tukak lambung seperti golongan fenol dan flavonoid. Metabolit sekunder tersebut dapat menangkal radikal bebas khususnya langsung pada lambung. Flavonoid dapat meningkatkan kadar eicosanoid sehingga meningkatkan ketersediaan dari arakidonat yang berhubungan dengan sintesis prostaglandin. Seperti yang telah diketahui bahwa prostaglandin merupakan salah satu faktor defensif di dalam lambung yang berperan dalam sintesis mukosa lambung. Selain itu juga, flavonoid dapat menstimulasi proliferasi seluler, meningkatkan ketahanan mucus, berefek antioksidan dan menghambat sekresi asam lambung sehingga dapat menyembuhkan tukak (Kirtida dkk., 2013).

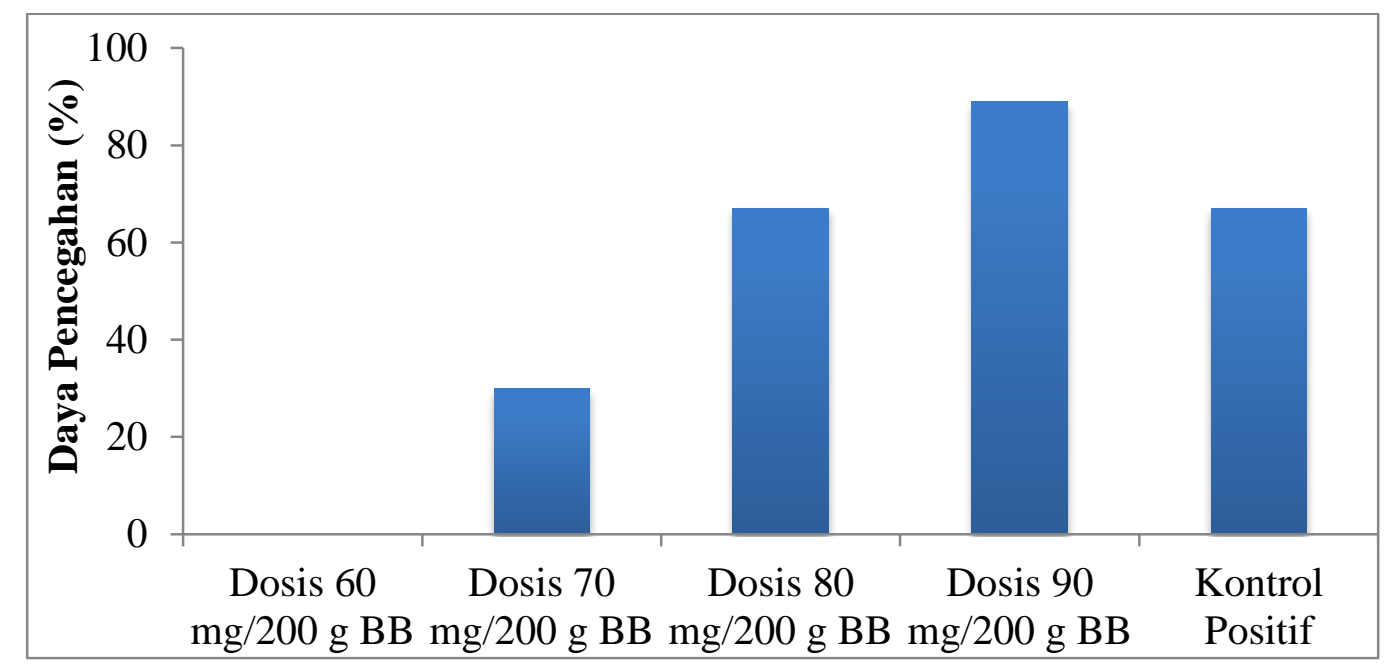

Gambar 1. Daya Pencegahan ekstrak metanol kulit pisang terhadap tukak lambung 


\section{Dosis Efektif dan Potensi Ekstrak Metanol Kulit Pisang Sebagai Antitukak Lambung}

Hasil analisis statistik menggunakan ANAVA satu arah dilanjutkan dengan uji Beda Nyata Jujur (BNJ). Uji BNJ digunakan karena didapatkan nilai koefisien keseragaman (KK) sebesar 2,65\% dimana syarat untuk dilakukan uji BNJ adalah nilai $\mathrm{KK}<5 \%$. Berdasarkan hasil uji BNJ diperoleh dosis efektif pada dosis $80 \mathrm{mg} / 200 \mathrm{~g} \mathrm{BB}$. Hal ini dikarenakan pada dosis $80 \mathrm{mg} / 200 \mathrm{~g}$ BB memiliki rerata indeks tukak yang tidak berbeda signifikan dengan kelompok kontrol positif (p>0,05). Meskipun pada dosis $90 \mathrm{mg} / 200 \mathrm{~g}$ BB memberikan hasil yang lebih baik namun untuk efisiensi jumlah bahan maka dipilih dosis $80 \mathrm{mg} / 200 \mathrm{~g}$ BB karena hasil yang didapatkan sudah menyamai hasil yang didapatkan pada kelompok kontrol positif. Hal tersebut juga mengindikasikan bahwa terdapat potensi dari ekstrak metanol kulit pisang sebagai antitukak lambung karena mampu menyamai hasil dari kelompok kontrol positif.

Pada gambar 1 terlihat bahwa semakin tinggi dosis ekstrak yang diberikan maka akan semakin besar pula daya pencegahannya terhadap tukak lambung pada hewan uji. Selain itu pada dosis 4 yaitu dosis $90 \mathrm{mg} / 200 \mathrm{~g}$ BB terlihat bahwa daya pencegahan yang dihasilkan lebih tinggi daripada daya pencegahan dari kontrol positif sehingga ekstrak metanol kulit pisang memiliki potensi yang cukup besar untuk digunakan sebagai antitukak lambung.

\section{KESIMPULAN}

Ekstrak metanol kulit pisang (Musa paradisiaca Linn.) memiliki aktivitas sebagai antitukak lambung dengan dosis efektif yaitu $80 \mathrm{mg} / 200 \mathrm{~g}$ BB serta memiliki potensi jika dibandingkan dengan Sukralfat.

\section{DAFTAR PUSTAKA}

Johnson, Ashley, Bryan Kratz, Lorraine Scanlon dan Alina Spivak, 2007, Guts and Glory H. pylori: Cause of peptic ulcer. Eukaryon. 3. 67-73

Pane, Elfira , 2013, Uji Aktivitas Senyawa Antioksidan dari Ekstrak Metanol Kulit Pisang Raja (Musa paradisiaca Sapientum). Valensi. 3. (2). 76-81.

Atun, Sri, Retro Arianingrum, Sri Handayani, Rudyansah dan Mary Garson, 2007, Identification and Antioxidant Activity Test of Some Compounds from Methanol Extract Peel of Banana (Musa paradisiaca Linn.). Indonesia Journal Chemistry. 7. (1). 83-87.

Atzingen, Denia, Alfredo Gragnani, Daniela Francescato, Luis Eduardo, Lorraine Lorene, Thiago Ricardo, Adriana Rodrigues dan Lydia Masako Ferreira, 2013, Unripe Musa sapientum peel in the Healing of Surgical Wounds in Rats. Acta Cirurgica Brasileira. 28. (1). 33-38.

Fitrianingsih, S. dan Choesrina, R., 2011, Uji Aktivitas Madu Sebagai Antitukak Lambung Terhadap Tikus Putih Galur Wistar. ISSN:2089-3582. 2. (1). 9-16

Tarnawski, A., 2004, Aspirin in the XXI century: Its Major Clinical Impact, Novel Mechanisms of Action and New Safer Formulation. Gastroenterology. 124. (23). 341348.

Kirtida, Tandel, Shah B.K. dan Deoghare Shashank, 2013. A Study of Ulcer Healing Effect of Vegetable Plantain Banana (Musa sapientum var. paradisiaca) on Aspirin Induced Gastric Ulcer in Rats. International Journal of Research in Pharmaceutical and Biomedical Sciences. 4. (1). 339-343 